\title{
Study on the adsorption behavior of modified persimmon powder biosorbent on $\operatorname{Pt}(\mathrm{IV})$
}

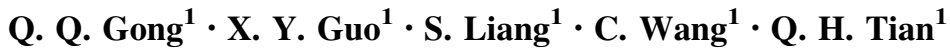

Received: 22 October 2012/Revised: 10 January 2015 / Accepted: 17 March 2015/Published online: 27 May 2015

(C) Islamic Azad University (IAU) 2015

\begin{abstract}
A glycine-modified persimmon powder was used as biosorbent for platinum adsorption in aqueous solution. The combined effects of modifying agent amount, modifying time and temperature on $\mathrm{Pt}(\mathrm{IV})$ adsorption by persimmon biosorbent were investigated, from which the optimum modification conditions with modifying agent amount of $50 \%$, temperature of $333 \mathrm{~K}$ and contact time of $4.0 \mathrm{~h}$ were determined. The influences of solution initial $\mathrm{pH}$, solid-to-liquid ratio, contact time, temperature and initial concentration on the Pt(IV) adsorption were studied systematically by batch experiments. The optimum modification conditions were determined as follows: chemical reagent amount of $50 \%$, temperature of $333 \mathrm{~K}$ and contact time of $4.0 \mathrm{~h}$. From the adsorption kinetic analysis, it was found that the adsorption kinetics of glycine-modified persimmon powder followed a pseudo-second-order kinetic model. The adsorption isotherms of the crude persimmon powder and glycine-modified persimmon powder were analyzed with the BET-type adsorption isotherm. The adsorption mechanism of Pt(IV) on the glycine-modified persimmon was considered to be adsorption-reduction mechanism. The results achieved from this study indicated that the novel persimmon adsorbent could be applied to recover trace $\mathrm{Pt}(\mathrm{IV})$ ions from a concentrated chloride solution.
\end{abstract}

Keywords Persimmon - Glycine - Platinum - Biosorption · BET isotherm

X. Y. Guo

xyguo@csu.edu.cn

1 School of Metallurgy and Environment, Central South University, Changsha 410083, China

\section{Introduction}

Platinum is widely used in ornaments, catalytic agent, energy materials and so on. Due to its high chemical stability as well as high conductivity, its consumption is growing increasingly in the past years. Because of the increasing demand along with the scarcity of natural platinum resources, how to efficiently treat the lowgrade natural ores and secondary resources containing platinum group metals has attracted much attention. In general, aqua regia and hydrochloric acid containing chloride ions are utilized to separate and recover platinum group metals from natural or secondary platinum resource (Parajuli et al. 2008a). Conventional methods used for recovering platinum from this type of leaching liquor include ion exchange, electrowinning, solvent extraction, etc. Certainly, these processes have several drawbacks including lower recovery efficiency, secondary contamination and cost ineffectiveness. Recently, biosorption technology has been found to be a simple and clean method to recover platinum from aqueous solution. Some of the adsorbents such as orange peel, grape wastes and rice husk (Parajuli et al. 2006; Ramesh et al. 2008; Parajuli et al. 2009) were used for removing toxic elements and recovering precious metals from aqueous solution.

Waste persimmon generated from forestry and agriculture is composed of tannin, pectin, cellulose and other low molecular weight hydrocarbons (Parajuli et al. 2008a). Some researchers have reported that the crosslinking persimmon exhibited outstanding adsorption capacity for $\mathrm{Au}(\mathrm{III})$ and the maximum platinum adsorption capacity reached $45.8 \mathrm{mg} / \mathrm{g}$ when using the bayberry tannin immobilized collagen fiber membrane (Gurung et al. 2011; Ma et al. 2006). 
This paper studies a novel glycine-modified persimmon powder for $\mathrm{Pt}(\mathrm{IV})$ from aqueous solution, and the adsorption mechanism of GPP is addressed. The modification is to introduce glycine into persimmon powder (abbreviated as PP) to synthesize an effective adsorbent based on Mannich reaction shown below.

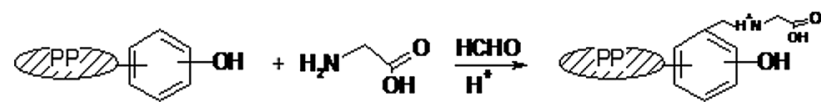

The effects of various parameters including solution initial $\mathrm{pH}$, contact time, temperature and solid-to-liquid ratio $(\mathrm{S} / \mathrm{L})$ on the adsorption efficiency of $\mathrm{Pt}(\mathrm{IV})$ were investigated.

Date of the research carried out is in the month of September 2012.
Location of date of the research carried out is at School of Metallurgical Science and Engineering, Central South University, Changsha, China.

\section{Materials and methods}

\section{Materials}

Stock solution was prepared by diluting analytical-grade $\mathrm{H}_{2} \mathrm{PtCl}_{6} \cdot \mathrm{H}_{2} \mathrm{O}$ using double-distilled water. $\mathrm{HCl}$ and $\mathrm{NaOH}$ with analytical purity were used to control the solution $\mathrm{pH}$. The analytical-grade $\mathrm{H}_{2} \mathrm{PtCl}_{6} \cdot \mathrm{H}_{2} \mathrm{O}$ was provided by $\mathrm{Na}$ tional Medicine Group Chemical Reagent Co., LTD. The crude waste persimmon used was kindly supplied by Bio Technology Co., in Shanxi Province of China.

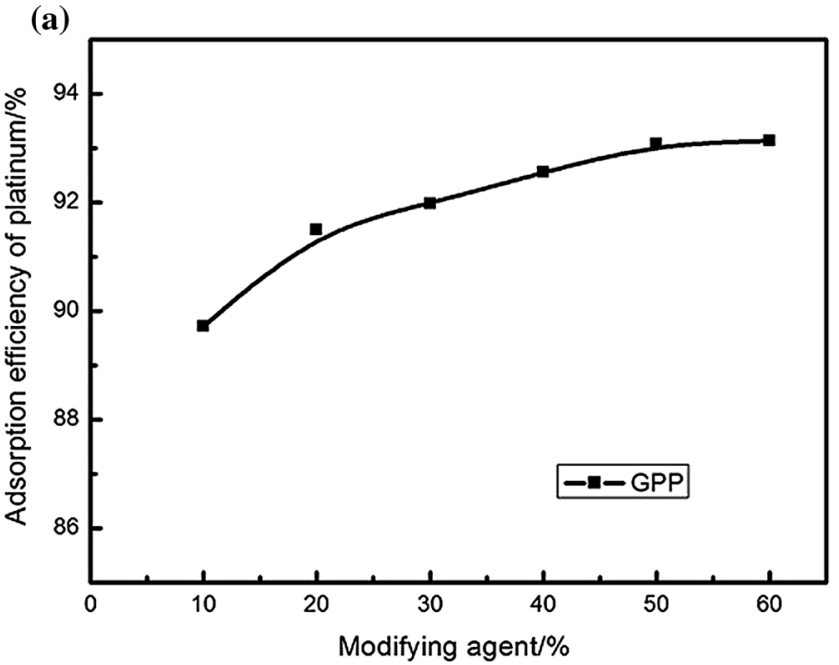

(b)

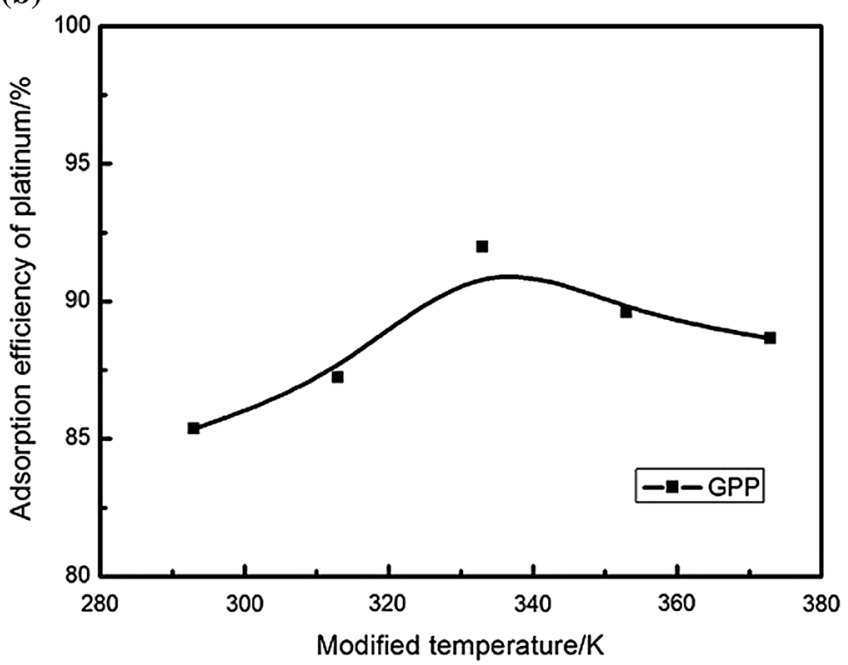

Fig. 1 Effect of chemical reagent amount, temperature and reaction time on persimmon modification. a The effect of chemical reagent amount (Conditions: temperature $-333 \mathrm{~K}$; reaction time $-4 \mathrm{~h}$; force air drying); $\mathbf{b}$ the effect of temperature (Conditions: chemical reagent (c)

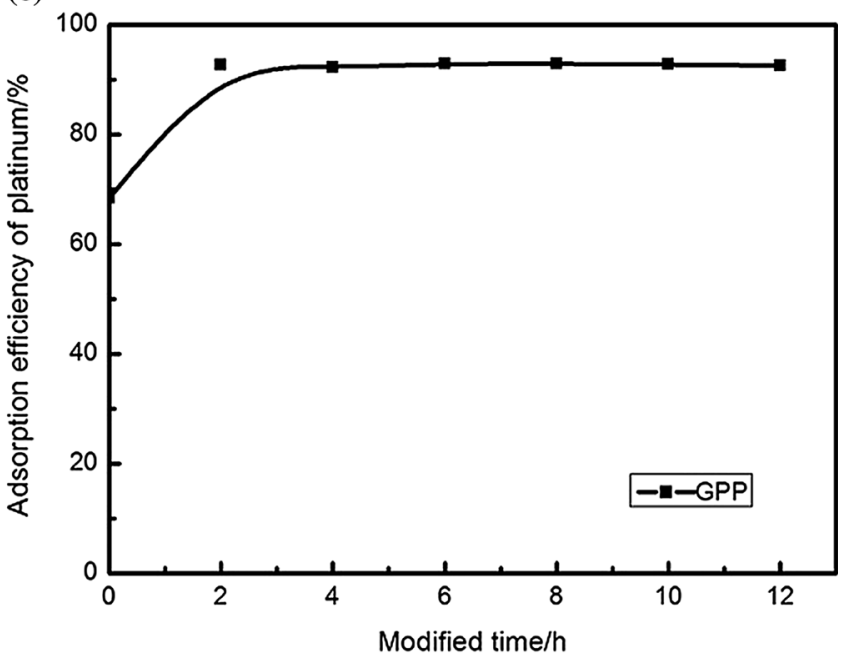

amount-50\%; reaction time $-4 \mathrm{~h}$; force air drying); $\mathbf{c}$ the effect of reaction time. (Conditions: chemical reagent amount-50\%; temperature- $333 \mathrm{~K}$; force air drying) 


\section{Preparation of persimmon powder (PP)}

The waste persimmon consisted of astringent persimmon fruit, was washed with double-distilled water and dried at $333 \mathrm{~K}$ in a convection oven for $24 \mathrm{~h}$. The dried persimmon was crushed and sieved to make the particle size lower than $0.40 \mathrm{~mm}$. Then, the obtained product was named as PP for further adsorption study.

\section{Modification experiments}

Modification experiments of PP were carried out by taking certain amounts of PP and modified agent (a mixture solution composed of glycine, formaldehyde and concentrated hydrochloric acid) together in a shaking bath by controlling definite modified temperature and contact time. Then, the modified product was filtered and washed with double-distilled water and dried in convection oven for $24 \mathrm{~h}$. Finally, through grinding and sieving, the glycine-modified persimmon powder (hereafter abbreviated as GPP) was obtained.

\section{Adsorption experiments}

A series of batch adsorption experiments for Pt(IV) were individually conducted in the shake bath under certain conditions by using GPP and PP as adsorbent, respectively. The effects of various parameters, including solution initial $\mathrm{pH}$, solid-to-liquid ratio, temperature, and adsorption kinetics and adsorption isotherms on the Pt(IV) adsorption process, were investigated. The adsorption kinetics of $\mathrm{Pt}(\mathrm{IV})$ were studied by taking $10 \mathrm{~mL}$ of Pt(IV) solution $(30 \mathrm{mg} / \mathrm{L})$ together with $50 \mathrm{mg}$ of GPP and shaking the mixture at various temperatures (303, 328 and $343 \mathrm{~K}$ ). Adsorption efficiency of $\mathrm{Pt}(\mathrm{IV})$ and the amount of adsorption (q, $\mathrm{mmol} / \mathrm{g}$ ) were calculated according to Eqs. 1 and 2, respectively:

Adsorption $\%=\frac{C_{0}-C_{\mathrm{e}}}{C_{0}} \times 100 \%$

$q=\frac{\left(C_{0}-C_{\mathrm{e}}\right) V}{m}$

where $C_{0}$ and $C_{\mathrm{e}}$ represent the initial and equilibrium Pt(IV) concentration $(\mathrm{mmol} / \mathrm{L})$, respectively; $V$ represents the volume of the solution (L), and $m$ is the mass of adsorbent (mg).

\section{Characterization methods}

The main functional groups on PP and GPP were characterized with a Fourier transform infrared spectrophotometer (Nicolet 380). Metal concentrations were measured by using a WFX-130-B atomic absorption spectrophotometer (AAS). The oxidation state of the platinum bound the biomaterial GPP was ascertained with X-ray photoelectron spectroscopy (K-Alpha 1063).

\section{Results and discussion}

\section{Chemical modification of persimmon powder (PP)}

\section{Effect of modifying agent amount}

In this paper, the modifying agent was a mixture solution consisting of glycine, formaldehyde and concentrated hydrochloric acid. The amount of modifier changed within the range of $10-60 \%$ (w/w\% calculated based on the mass of PP); the efficiency of modified GPP was addressed by adsorption of $\mathrm{Pt}(\mathrm{IV})$, and the results are presented in Fig. 1a. It shows that the adsorption ability of GPP on Pt(IV) can be enhanced when increasing the modifier amount. This is because that modification reaction of PP is promoted and almost all of PP has been converted to GPP as the modifying reagent content increasing.

\section{Effect of modification temperature}

In order to elucidate the effect of temperature on the modification of PP, the experiments were conducted with the mixtures containing $1.0 \mathrm{~g} \mathrm{PP}$ and $0.5 \mathrm{~g}$ modification reagent at various temperatures to address the behavior of GPP on adsorption of $\mathrm{Pt}(\mathrm{IV})$ and the results are shown in Fig. 1b. It can be seen that when the temperature increases from 293 to $333 \mathrm{~K}$, the Pt(IV) adsorption by GPP increases slowly. Further increasing modified temperature, the Pt(IV) adsorption tends to decrease, which can be ascribed to the dissolution and decomposition of active ingredients in persimmon, thus hindering the Mannich reaction occurrence (Adhikari et al. 2008).

\section{Effect of modification time}

In these experiments, the modification time is optimized in the range of $0-12 \mathrm{~h}$. The results shown in Fig. 1c illustrate that during the first four hours of reaction, the Pt(IV) adsorption by GPP is enhanced (Ren et al. 2007). Then, the $\mathrm{Pt}(\mathrm{IV})$ adsorption tends to be constant along with further increasing of time.

In conclusion, the optimum modification conditions were determined as follows: chemical reagent amount of $50 \%$, temperature of $333 \mathrm{~K}$ and temperature of $4.0 \mathrm{~h}$.

\section{FT-IR analysis}

The FT-IR spectrums of PP and GPP obtained under the optimum modification conditions are shown in Fig. 2. For $\mathrm{PP}$, the broad adsorption peak at $3288.0 \mathrm{~cm}^{-1}$ corresponds to the $\mathrm{O}-\mathrm{H}$ stretching vibrations of tannin, pectin and cellulose, thus showing the presence of "free" hydroxyl groups on the adsorbent surface. The peak observed at 


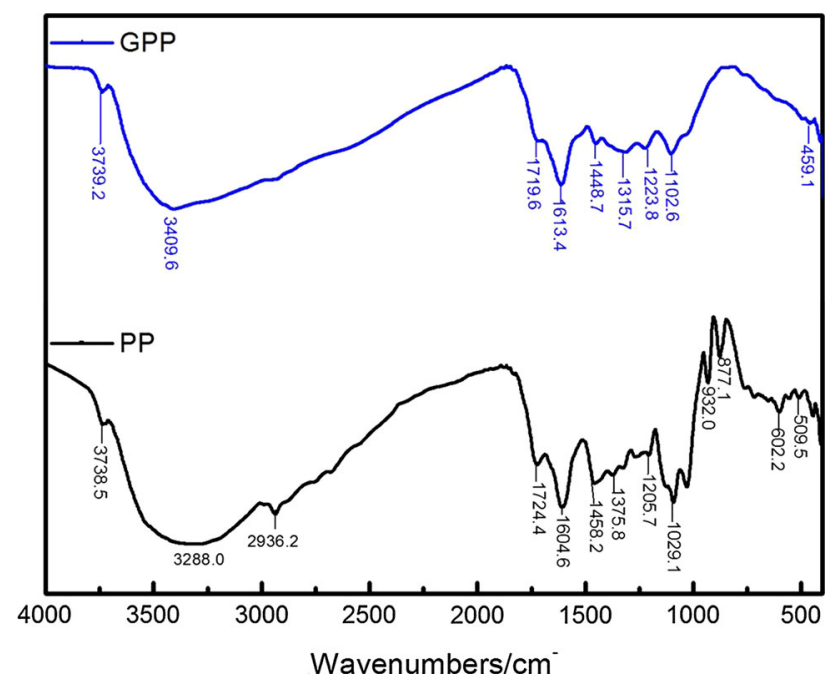

Fig. 2 FT-IR spectrums of PP and GPP

$2936.2 \mathrm{~cm}^{-1}$ can be attributed to the $\mathrm{C}-\mathrm{H}$ stretching vibrations of methyl and methylene (Feng et al. 2009). The peaks observed at $1724.4 \mathrm{~cm}^{-1}$ can be attributed to the carbonyl $(\mathrm{C}=\mathrm{O})$ stretching vibration of free carboxyl groups of catechin, catechol and gallic acid (Kim et al. 2007). The peaks at 1604.6 and $1458.2 \mathrm{~cm}^{-1}$ are due to the carbonyl $(\mathrm{C}=\mathrm{O})$ symmetrical and asymmetrical stretching vibrations of free ionization carboxyl in pectin and tannin acid. The vibration of hydroxyl $(-\mathrm{OH})$ of aryl group in tannin and lignin appears at 1375.8 and $1205.7 \mathrm{~cm}^{-1}$. The peaks at 932.0 and $877.1 \mathrm{~cm}^{-1}$ show the $\mathrm{C}=\mathrm{C}$ bond stretching vibration. The broad peak at $3288.0 \mathrm{~cm}^{-1}$ in the PP becomes narrow and shifts to $3409 \mathrm{~cm}^{-1}$ in the GPP, which indicates that the $\mathrm{O}-\mathrm{H}$ is involved in the modification. The shifting of the free ionization carboxy $(\mathrm{C}=\mathrm{O})$ peaks is attributed to the polymerization during the modification (Liang et al. 2010a). Moreover, two new peaks at 1315.7 and $459.1 \mathrm{~cm}^{-1}$ are due to amino $(\mathrm{N}-\mathrm{H})$ stretching, which infers the polyphenol groups have combined with glycine (Xiong et al. 2009).

\section{Adsorption experiments}

\section{Effect of initial solution $p H$ on Pt(IV) adsorption}

The solution $\mathrm{pH}$ can influence the functional groups on the bio-absorbents and ion behavior in aqueous solution. Figure $3 \mathrm{a}$ gives the effect of initial solution $\mathrm{pH}$ on adsorption of Pt(IV) by PP and GPP. It is found that GPP shows better adsorption ability than that of PP. The adsorption efficiency increases as the initial solution $\mathrm{pH}$ changes from 0.4 to 2.4 . And when the initial solution $\mathrm{pH}$ is above 2.4, the adsorption efficiency decreases slightly. When the $\mathrm{pH}$ value is below 0.4 , the concentration of $\mathrm{PtCl}_{6}{ }^{-}$increases in the solution, which hinders the adsorbing of $\mathrm{Pt}(\mathrm{IV})$ (Gurung et al. 2011). Through increasing solution initial $\mathrm{pH}$ properly, the activity of $\mathrm{PtCl}_{6}{ }^{-}$can be enhanced and more Pt(IV) will be bound on the adsorbents, thus leading to the increase in the adsorption efficiency. Further increasing of $\mathrm{pH}$ may lead to hydrolysis of $\mathrm{PtCl}_{6}{ }^{-}$to form $\mathrm{Pt}(\mathrm{OH})_{2}$, and $\mathrm{Pt}(\mathrm{OH})_{4}$ (Byrne and Yao 2000; Parajuli et al. 2009).

\section{Effect of temperature on Pt(IV) adsorption}

The effect of temperature on the adsorption efficiency of $\mathrm{Pt}(\mathrm{IV})$ is studied over the temperature range of $298-358 \mathrm{~K}$. The results are presented in Fig. 3b. It is shown that the $\mathrm{Pt}(\mathrm{IV})$ adsorption on GPP is strengthened by increasing temperature below $343 \mathrm{~K}$. Further increasing the temperature has less effect on the adsorption efficiency. This is because that high temperature enhances adsorption, (Feng et al. 2009; Cox et al. 2005). However, temperature has a negative effect on the adsorption when using PP, which may be attributed to increased solubility of PP which consequently weakens the Pt(IV) adsorption by PP as increasing the temperature (Duan et al. 2007).

\section{Effect of solid-to-liquid ratio(S/L) on Pt(IV) adsorption}

In order to determine an efficient and cost-effective process to recover platinum, the optimum solid-to-liquid ratio (mass of adsorbent to volume of metal ion solution, $\mathrm{S} / \mathrm{L}$ ) was determined as shown in Fig. 3c. It is illustrated that the adsorption efficiency of GPP is enhanced as S/L increases from 1.0 to $11.0 \mathrm{~g} / \mathrm{L}$. Further increasing $\mathrm{S} / \mathrm{L}$ has a negligible impact on the adsorption efficiency. It is supposed that most of active metal ions can been adsorbed on the surface of GPP when the S/L reaches $11.0 \mathrm{~g} / \mathrm{L}$. However, PP shows a reverse tendency compared to GPP, which may be mainly attributed to the aggregation of $\mathrm{PP}$ in the solution hindering the adsorption of $\mathrm{Pt}(\mathrm{IV})$. When $\mathrm{S} / \mathrm{L}$ is lower than $7.0 \mathrm{~g} / \mathrm{L}$, the aggregation of PP plays a primary role in the adsorption process, thus leading to the decrease in adsorption efficiency. When $\mathrm{S} / \mathrm{L}$ is extremely large, despite of the presence of aggregation, some spare PP still can be remained to adsorb $\mathrm{Pt}(\mathrm{IV})$.

\section{Adsorption kinetics of Pt(IV)}

The investigation of contact time effect was carried out over the time range of $30-720 \mathrm{~min}$ at different temperatures, and the results are presented in Fig. 4. It can be seen that adsorption equilibrium at 298, 328 and $343 \mathrm{~K}$ could be reached within 8,6 and $4 \mathrm{~h}$, respectively.

The adsorption kinetics of $\mathrm{Pt}(\mathrm{IV})$ on GPP is studied by monitoring the $\mathrm{Pt}(\mathrm{IV})$ concentration remained in the aqueous solution at different temperatures. The observed data are analyzed in terms of the pseudo-second-order 
model which assumes that the efficiency is proportional to the square of the number $R$. The kinetic model can be expressed as Eq. 3 (Liang et al. 2010b):

$\frac{t}{q_{\mathrm{t}}}=\frac{1}{k q_{\mathrm{e}}^{2}}+\frac{t}{q_{\mathrm{e}}}$

where $q_{\mathrm{e}}$ and $q_{\mathrm{t}}$ are the amounts of the adsorption of $\mathrm{Pt}$ $(\mathrm{mmol} / \mathrm{g})$ at equilibrium and at time $t(\mathrm{~min})$, respectively; $k$ is the constant of pseudo-second-order rate. The equilibrium adsorption amount $q_{\mathrm{e}}$ and pseudo-second-order efficiency constant $k$ can be derived from the slope and the intercept of the plot $t / q_{\mathrm{t}}$. The results are shown in Table 1 . From Table $1, R^{2}>0.9998$ is obtained for different temperature and theoretical values of $q_{\mathrm{e}}$ can agree well with the experimental values, indicating that the adsorption is fit to pseudo-second-order kinetic model and the adsorption reaction rate is controlled by chemical adsorption (Kim et al. 2007; Liu and Liu 2008a).

Moreover, according to the Eqs. 4 and 5, the standard free energy $\left(\Delta G^{\mathrm{o}}\right)$, enthalpy $\left(\Delta H^{\mathrm{o}}\right)$ and entropy change $\left(\Delta S^{\mathrm{o}}\right)$ thermodynamic parameters were calculated and illustrated in Table 2.

$K_{\mathrm{c}}=C_{\delta} / C_{\mathrm{e}}$

$\ln K_{\mathrm{c}}=-\frac{\Delta G^{\mathrm{o}}}{\mathrm{RT}}=-\frac{\Delta H^{\mathrm{o}}}{\mathrm{RT}}+\frac{\Delta S^{\mathrm{o}}}{R}$

where $K_{\mathrm{c}}$ is the thermodynamic equilibrium constant, $C_{\delta}$ is $\mathrm{mg}$ of adsorbate adsorbed per liter and $C_{\mathrm{e}}$ is the equilibrium concentration of solution, $\mathrm{mg} / \mathrm{L}$.

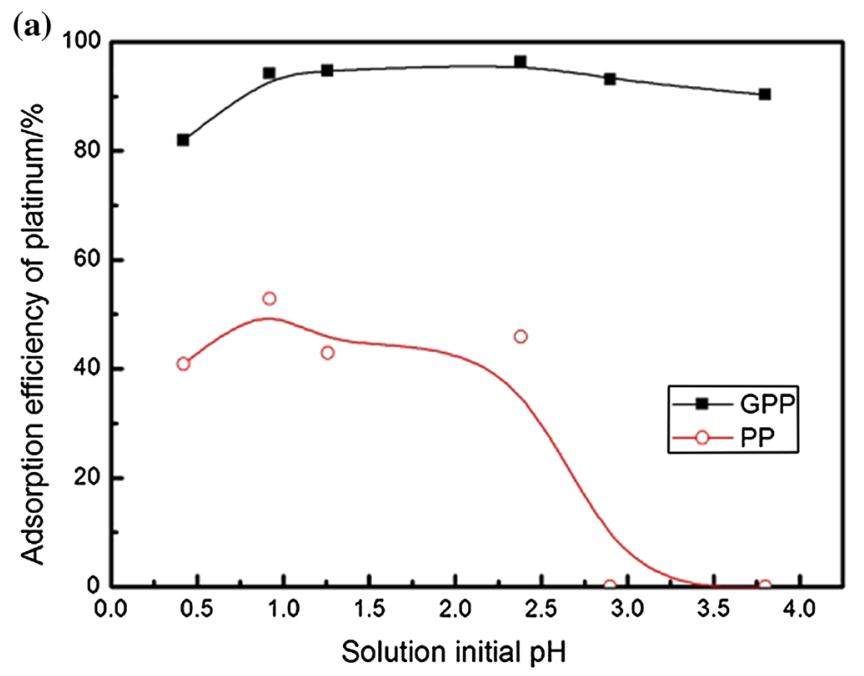

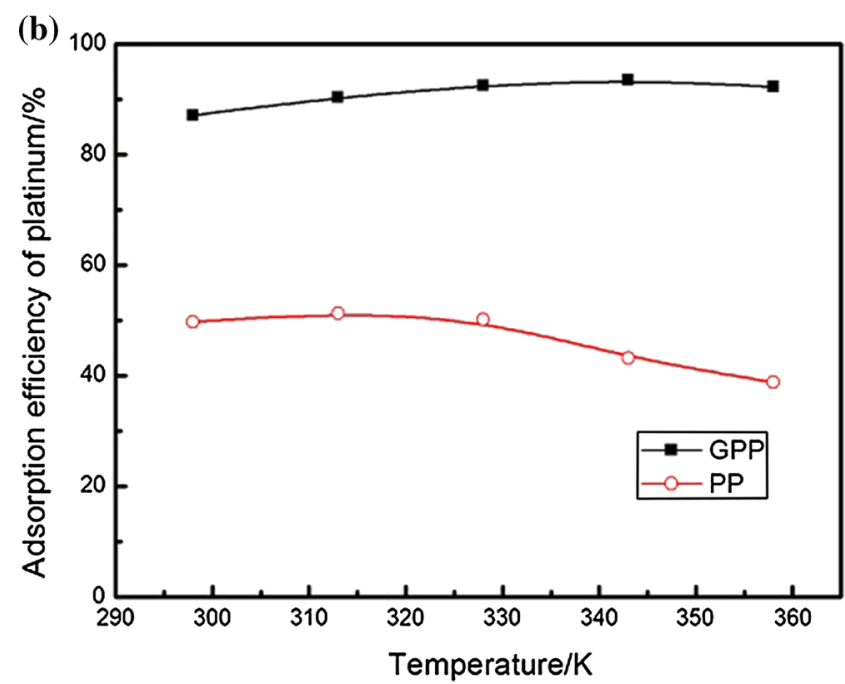

Fig. 3 Effect of solution initial $\mathrm{pH}$, temperature and $\mathrm{S} / \mathrm{L}$ on the adsorption efficiency of Pt(IV). a The effect of solution initial $\mathrm{pH}$ (Conditions: temperature-333 K; S/L: $5.0 \mathrm{~g} / \mathrm{L}$; time: $24 \mathrm{~h}$; $\mathrm{Pt}(\mathrm{IV})$ concentration- $0.15 \mathrm{mmol} / \mathrm{L}) ; \quad \mathbf{b}$ the effect of temperature

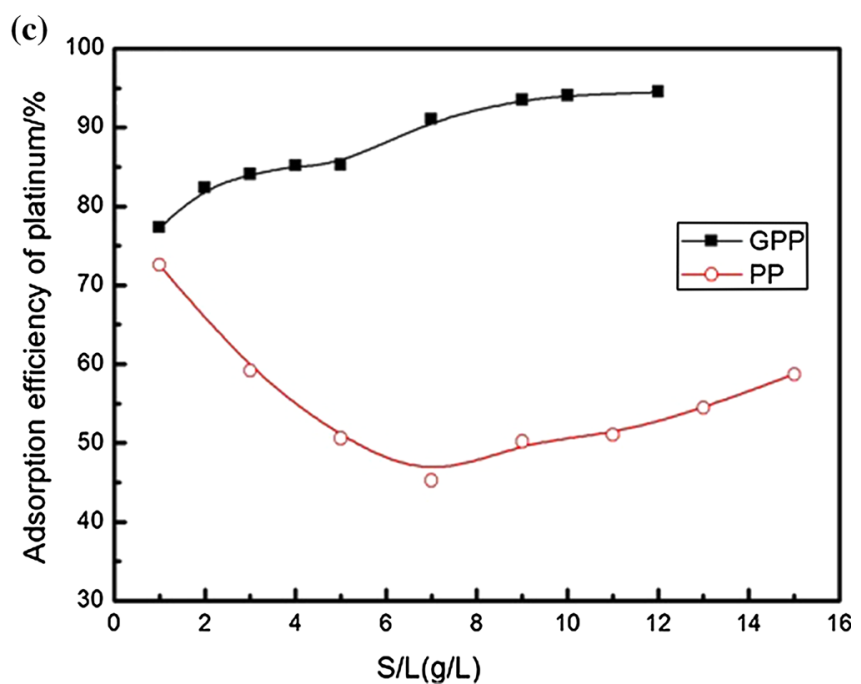

(Conditions: initial pH: 0.9; $\mathrm{S} / \mathrm{L}-5.0 \mathrm{~g} / \mathrm{L} ;$ time $-24 \mathrm{~h} ; \mathrm{Pt}(\mathrm{IV})$ concentration- $0.15 \mathrm{mmol} / \mathrm{L}$ ); $\mathbf{c}$ the effect of S/L (Conditions: $\mathrm{Pt}(\mathrm{IV}$ ) concentration- $0.15 \mathrm{mmol} / \mathrm{L} ;$ solution $\mathrm{pH}-0.9$; temperature$343 \mathrm{~K}$; time-24 h) 
From Table 2, it can be seen that the standard free energy $\left(\Delta G^{\mathrm{o}}\right)$ is negative at 298,328 and $343 \mathrm{~K}$, which indicates the adsorption process can occur spontaneously, while the values of $\Delta H^{\mathrm{o}}$ and $\Delta S^{\mathrm{o}}$ calculated from the slope and the intercept of the Eq. 4 are 143.90 and $0.53 \mathrm{~kJ} / \mathrm{mol}$, respectively. According to the study of Liu et al. (Liu and Liu $2008 \mathrm{~b})$, the enthalpy change $\left(\Delta H^{\circ}\right)$ of physical adsorption is below $4.18 \mathrm{~kJ} / \mathrm{mol}$ while that of chemical adsorption is over $20.92 \mathrm{~kJ} / \mathrm{mol}$. Based on the values of enthalpy change $\Delta H^{\mathrm{o}}$, it is concluded that the Pt(IV) adsorption on the GPP studied here would be attributed to a chemical adsorption process. The positive value of $\Delta H^{\mathrm{o}}$ indicates the endothermic nature of process by GPP. The low value of $\Delta S^{\mathrm{o}}$ may suggest that no considerable change in entropy occurs during the $\mathrm{Pt}(\mathrm{IV})$ adsorption process on the GPP.

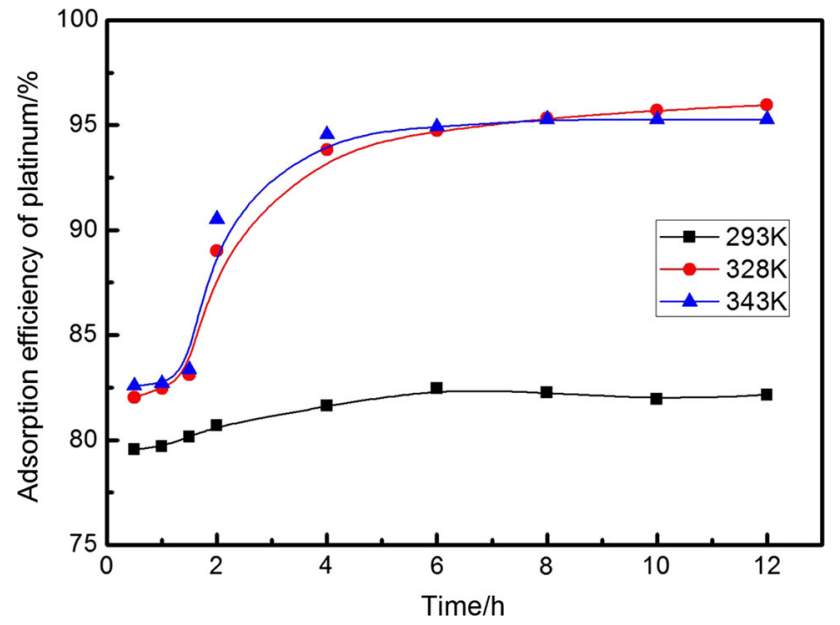

Fig. 4 Effect of contact time on the adsorption efficiency of Pt(IV). (Conditions: solution $\mathrm{pH}$ : $0.9 ; \mathrm{S} / \mathrm{L}: 5.0 \mathrm{~g} / \mathrm{L} ; \mathrm{Pt}(\mathrm{IV})$ concentration: $0.15 \mathrm{mmol} / \mathrm{L}$ )

Table 1 Kinetic parameters of the pseudo-second-order for Pt(IV) adsorption

\begin{tabular}{lllll}
\hline $\begin{array}{l}\text { Temperature } \\
(\mathrm{K})\end{array}$ & $q_{\mathrm{t}}(\mathrm{mmol} / \mathrm{g})$ & \multicolumn{3}{l}{ Pseudo-second-order kinetic model } \\
\cline { 3 - 5 } & & $q_{\mathrm{e}}(\mathrm{mg} / \mathrm{g})$ & $K[\mathrm{~g}(\mathrm{mg}$ min $)]$ & $R^{2}$ \\
\hline 298 & 0.12 & 0.12 & 0.0025 & 0.9999 \\
328 & 0.17 & 0.17 & 0.0028 & 0.9998 \\
343 & 0.17 & 0.17 & 0.0027 & 0.9998 \\
\hline
\end{tabular}

Table 2 Thermodynamic parameters for the adsorption of Pt(IV) by GPP

\begin{tabular}{llllll}
\hline Adsorbent & $\begin{array}{l}\text { Temperature } \\
(\mathrm{K})\end{array}$ & $K_{\mathrm{c}}$ & $\begin{array}{l}\Delta G^{\mathrm{o}} \\
(\mathrm{kJ} / \mathrm{mol})\end{array}$ & $\begin{array}{l}\Delta H^{\mathrm{o}} \\
(\mathrm{kJ} / \mathrm{mol})\end{array}$ & $\begin{array}{l}\Delta S^{\mathrm{o}} \\
(\mathrm{kJ} / \mathrm{mol})\end{array}$ \\
\hline GPP & 298 & 1.91 & -16.67 & 143.90 & 0.53 \\
& 328 & 2.51 & -33.54 & & \\
& 343 & 2.65 & -40.51 & & \\
\hline
\end{tabular}

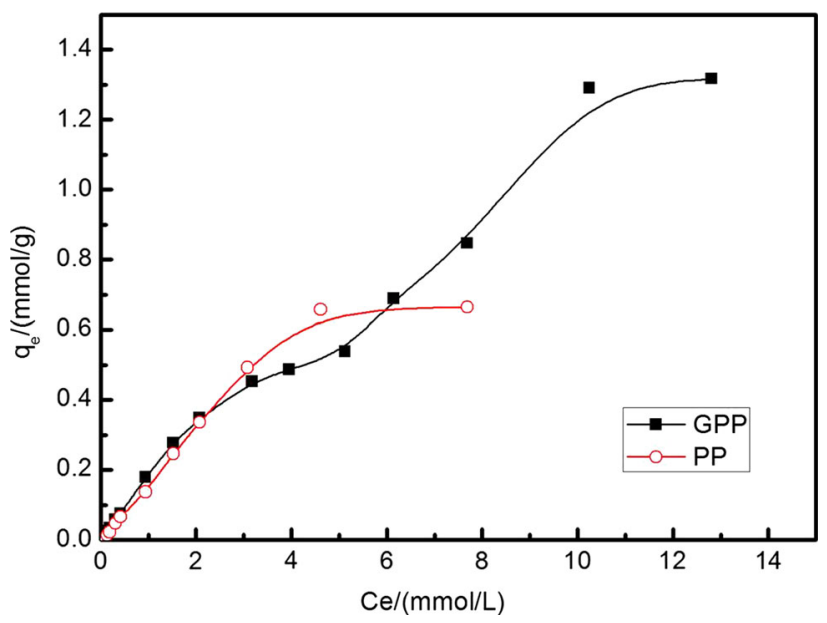

Fig. 5 Effect of initial $\mathrm{Pt}(\mathrm{IV})$ concentration on the adsorption efficiency of $\mathrm{Pt}(\mathrm{IV})$. (Conditions: solution $\mathrm{pH}$ : 0.9; S/L: $5.0 \mathrm{~g} / \mathrm{L}$; time: $24 \mathrm{~h}$; temperature: $343 \mathrm{~K}$ )

\section{Adsorption isotherms of Pt(IV)}

Figure 5 shows the effects of initial Pt(IV) concentration on the adsorption by PP and GPP. As revealed, Pt(IV) adsorption capacities of both adsorbents tend to approach the constant values at around $100 \mathrm{mg} / \mathrm{g}$. Interestingly, $\mathrm{Pt}(\mathrm{IV})$ adsorption capacity of GPP continues to rise with a further increasing in $\mathrm{Pt}(\mathrm{IV})$ concentration, which is consistent with a typical BET-type adsorption isotherm based on multilayer adsorption model. Such BET type of adsorption behavior for $\mathrm{Pt}(\mathrm{IV})$ is also reported on lemon peel gel (Gurung et al. 2011). Consequently, the platinum adsorption capacity of GPP reaches as high as $250 \mathrm{mg} / \mathrm{g}$.

Additionally, the results also indicate that the glycinemodified persimmon (GPP) is more effective than the crude persimmon powder (PP) for $\mathrm{Pt}(\mathrm{IV})$ adsorption from hydrochloric acid. It may be due to the improvement in surface morphology of the polymer matrices after chemical modification, which makes the GPP be mechanically strong and practically insoluble under the experimental condition. This is benefit for adsorption Pt(IV) from a concentrated chloride solution (Nakajima et al. 2003).

Table 3 shows the comparison of the maximum Pt(IV) adsorption capacities of different biomass-based adsorbents reported in different literatures. It can be seen the adsorption capacity of Pt(IV) by GPP in this work demonstrates remarkably highest capacity than that of other adsorbents.

\section{Adsorption mechanism}

Such a considerably high loading capacity of tannin-based adsorbents is supposed to involve the reduction in adsorbed $\mathrm{Pt}(\mathrm{IV})$ to the metallic $\mathrm{Pt}$ by polyphenols in the tannin molecules in persimmon. 
Table 3 Adsorption capacities of different adsorbents toward $\mathrm{Pt}(\mathrm{IV})$

\begin{tabular}{|c|c|c|c|}
\hline Adsorbents & $q(\mathrm{mmol} / \mathrm{g})$ & Conditions & References \\
\hline DMA persimmon waste gel (DMA-PW) & 0.28 & $\mathrm{HCl} 0.1 \mathrm{~mol} / \mathrm{L}$ & Xiong et al. (2009) \\
\hline Crosslinked grape waste & 0.29 & $\mathrm{pH}=1.0$ & Parajuli et al. (2008a) \\
\hline Crosslinked lignophenol gel & 0.56 & $\mathrm{HCl} 0.5 \mathrm{~mol} / \mathrm{L}$ & Parajuli et al. (2008b) \\
\hline Collagen fiber immobilized bayberry tannin & 0.61 & $\mathrm{HCl} 0.1 \mathrm{~mol} / \mathrm{L}$ & Ma et al. (2006) \\
\hline Carbonaceous sorbent prepared from flax shive & 0.98 & $\mathrm{pH}=1.0$ & Cox et al. (2005) \\
\hline GPP & 1.28 & $\mathrm{pH}=1.0$ & This work \\
\hline PP & 0.69 & $\mathrm{pH}=1.0$ & This work \\
\hline
\end{tabular}
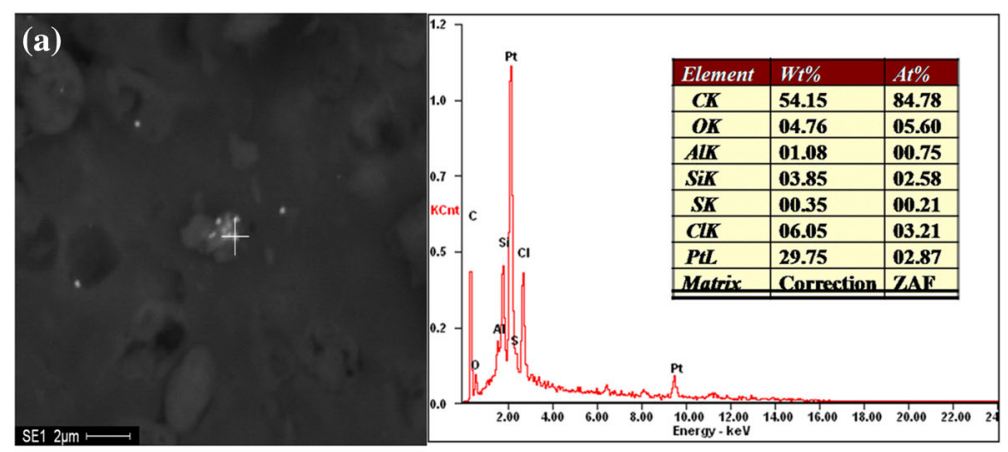

(b)
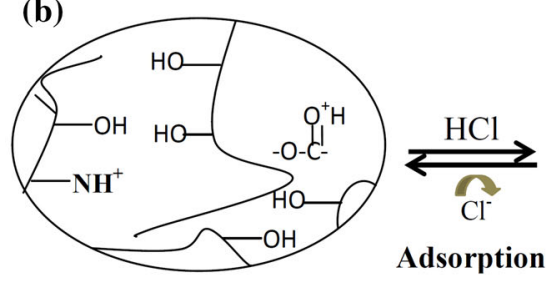

Adsorption
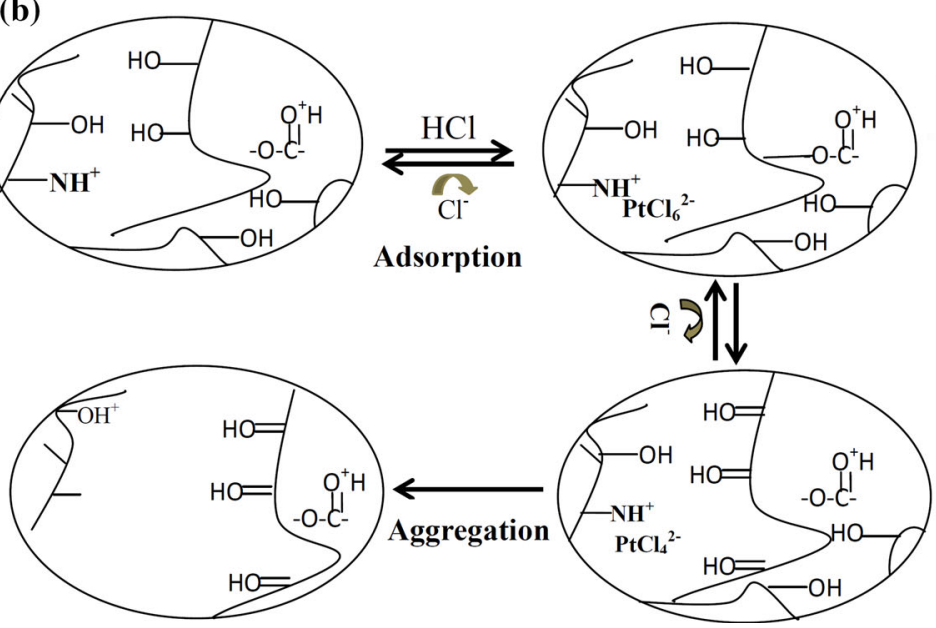

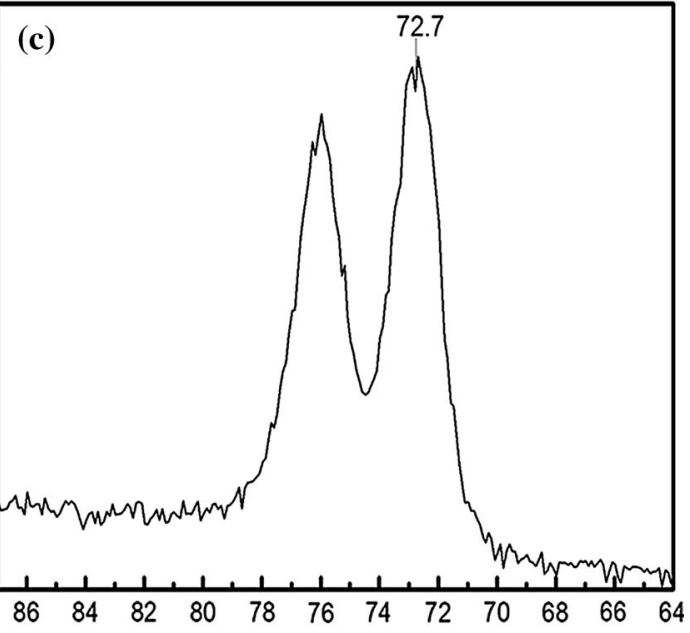

Binding energy/eV

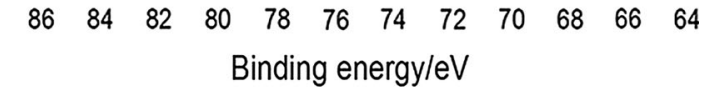

Fig. 6 Mechanism analysis of platinum adsorption on GPP and PP. a The EDS image of GPP after adsorbed platinum; $\mathbf{b}$ inferred mechanism of platinum adsorption; $\mathbf{c}$ high-resolution XPS spectra of the Pt-loaded GPP

Through introducing the electron-donating group $\left(\mathrm{NH}_{2}\right.$ $\mathrm{CH}_{2} \mathrm{COOH}$ ) to the aromatic rings, the interaction between $\mathrm{Pt}(\mathrm{IV})$ and the polyphonic groups in the tannin at acidic $\mathrm{pH}$ will be enhanced. However, this interaction is mostly dependent on the species of Pt(IV) existed in hydrochloric acid solution. As reported in the literatures, the chemical form of $\mathrm{Pt}(\mathrm{IV})$ is mainly $\mathrm{PtCl}_{6}{ }^{2-}$ in aqueous solution at $\mathrm{pH}$ of 1.0 (Chu 1983). Figure 6a shows the EDS of GPP-loaded platinum. As seen, the main elements of the adsorbent were $\mathrm{C}, \mathrm{Cl}$ and $\mathrm{Pt}$, which demonstrates that platinum in the aqueous solution can be adsorbed on the GPP through chelating, ionic-exchange and reduction.

Moreover, the standard reduction potentials of $E_{\mathrm{Pt}^{4+} / \mathrm{Pt}^{2+}}^{\Theta}$ and $E_{\mathrm{Pt}^{2+} / \mathrm{Pt}^{0}}^{\Theta}$ are 0.68 and $0.73 \mathrm{~V}$, respectively, which are significantly higher than that of $\mathrm{H}^{+}$(the standard reduction potential is $0.0 \mathrm{~V}$ ), thus ensuring the reduction reaction of $\mathrm{Pt}(\mathrm{IV})$ preferentially ongoing (Chu 1983) as the reaction of tannin with $\mathrm{Au}(\mathrm{IV})$ (Gurung et al. 2011). Therefore, the mechanism of platinum adsorption on the GPP and PP consists of three steps as presented in Fig. 6b:

1. The electrostatic adsorption step: the anionic species of platinum combines with the positively charged adsorbent GPP.

2. The reduction step: high valance of platinum is reduced to low valance platinum $\mathrm{Pt}(\mathrm{II})$.

3. The aggregation step: the elemental platinum aggregates to the bigger particles of platinum. 
Meanwhile, the complex reaction of $\mathrm{Pt}(\mathrm{IV})$ with polyphonic groups presents in the adsorption process.

To test the mechanism of $\mathrm{Pt}(\mathrm{IV})$ adsorption, it is very important to ascertain the oxidation state of the platinum bound on the biomaterial. Thus, high-resolution XPS spectra was carried out, and the data are collected from the Pt $4 \mathrm{f}$ core regions of the Pt-loaded biomaterial as well as standard $\mathrm{Pt}(\mathrm{IV})$ and $\mathrm{Pt}(\mathrm{IV})$ compounds (Fig. 6c). As shown in this figure, the spectra of the Pt-loaded biomaterial are well matched with those of standard $\mathrm{Pt}(\mathrm{IV})$ compounds $\left(\mathrm{K}_{2} \mathrm{PtCl}_{4}\right)$. This result states that the platinum bound on the biomaterial is mostly or totally in divalent form. Therefore, it can be concluded that the adsorption mechanism of $\mathrm{Pt}(\mathrm{IV})$ on the GPP is the adsorption-reduction mechanism, that is, $\mathrm{Pt}(\mathrm{IV})$ can be reduced to $\mathrm{Pt}(\mathrm{IV})$ in the aqueous and solid phase.

\section{Conclusion}

The glycine-modified persimmon adsorbent (GPP) studied in this paper has considerable potential as an efficient and useful adsorbent to recover Pt(IV) from a hydrochloric acid solution. FITR study illustrated the involvement of amino groups in the Mannich reaction process. The adsorption efficiency of $\mathrm{Pt}(\mathrm{IV})$ of GPP reached $96 \%$ under the optimum modification conditions with modified agent amount of $50 \%$, modified time of $4 \mathrm{~h}$ and temperature of $353 \mathrm{~K}$. For $\mathrm{PP}$ and GPP, solution initial $\mathrm{pH}$ had an obvious influence on adsorption efficiency. When $\mathrm{pH}$ value was 2.4 , almost $93 \%$ $\mathrm{Pt}(\mathrm{IV})$ ions were adsorbed. All of active platinum ions had been adsorbed on the surface of GPP when the S/L was $11.0 \mathrm{~g} / \mathrm{L}$. The $\mathrm{Pt}(\mathrm{IV})$ adsorption kinetics followed the pseudo-second-order kinetics. A typical BET-type adsorption isotherm was applied to explain the $\mathrm{Pt}(\mathrm{IV})$ adsorption based on multilayer adsorption model. The high platinum uptake capacity of GPP of $250 \mathrm{mg} / \mathrm{g}$ was attributed to the adsorption-coupled reduction. From these results, it is concluded the glycine-modified persimmon (GPP) can be expected to be used to recover platinum group metals from a concentrated hydrochloric acid solution because of its chemical stability high adsorption capacity and fast efficiency.

Acknowledgments This work was funded by the National Natural Science Foundation of China (Projects 50774100).

\section{References}

Adhikari CR, Parajuli D, Kawakita H, Inoue K, Ohto K, Harada H (2008) Dimethylamine-modified waste paper for the recovery of precious metals. Environ Sci Technol 42(15):5486-5491
Byrne RH, Yao W (2000) Formation of palladium(II) hydroxychloride complexes and precipitates in sodium chloride solutions and seawater. Geochim Cosmochim Acta 64(24):4153-4156

Chu J (1983) Thermodynamic analysis of platinum extraction. Precious Met 1(1):1-7

Cox M, Pichugin AA, El-Shafey EI, Appleton Q (2005) Sorption of precious metals onto chemically prepared carbon from flax shive. Hydrometallurgy 78(1-2):137-144

Duan WG, Geng Z, Tan LM (2007) The extraction of condensed tannin from black wattle bark. J Guangxi Univ (Nat Sci Ed) 32(2):138-142

Feng NC, Guo XY, Liang S (2009) Adsorption study of copper(II) by chemically modified orange peel. J Hazard Mater 164(2-3):1286-1292

Gurung M, Adhikari BB, Kawakita H, Ohto K, Inoue K, Alam S (2011) Recovery of $\mathrm{Au}$ (III) by using low cost adsorbent prepared from persimmon tannin extract. Chem Eng J 63(2):251-270

Kim YH, Ogata T, Nakano Y (2007) Kinetic analysis of palladium(II) adsorption process on condensed-tannin gel based on redox reaction models. Water Res 41(14):3043-3050

Liang S, Guo XY, Feng NC et al (2010a) Effective removal of heavy metals from aqueous solutions by orange peel xanthate. Trans Nonferrous Met Soc China, Supplement 20(1):s187-s191

Liang S, Guo XY, Feng NC, Tian Q (2010b) Isotherms, kinetics and thermodynamic studies of adsorption of $\mathrm{Cu}^{2+}$ from aqueous solutions by $\mathrm{Mg}^{2+} / \mathrm{K}^{+}$type orange peel adsorbents. J Hazard Mater 174(1-3):756-762

Liu Y, Liu YJ (2008a) Biosorption isotherms, kinetics and thermodynamics. Sep Purif Technol 61(3):229-242

Liu Y, Liu YJ (2008b) Reply to "Comments on "Biosorption isotherms, kinetics and thermodynamics" review". Sep Purif Technol 63(2):250

Ma H, Liao X, Liu X, Shi B (2006) Recovery of platinum(IV) and palladium(II) by bayberry tannin immobilized collagen fiber membrane from water solution. J Membr Sci 278(1):373-380

Nakajima A, Ohe K, Baba Y, Kijima T (2003) Mechanism of gold adsorption by persimmon tannin gel. Anal Sci 19(7):1075-1077

Parajuli D, Kawakita H, Inoue K, Funaoka M (2006) Recovery of gold(III), palladium(II), and platinum(IV) by aminated lignin derivatives. Ind Eng Chem Res 45(19):6405-6412

Parajuli D, Inoue K, Kawakita H, Ohto K, Harada H, Funaoka M (2008a) Recovery of precious metals using lignophenol compounds. Miner Eng 21(1):61-64

Parajuli D, Adhikari CR, Kawakita H, Kajiyama K, Ohto K, Inoue K (2008b) Reduction and accumulation of $\mathrm{Au}(\mathrm{III})$ by grape waste: a kinetic approach. React Funct Polym 68(8):1194-1199

Parajuli D, Khunathai K, Adhikari CR, Inoue K, Ohto K, Kawakita H, Funaoka M, Hirota K (2009) Total recovery of gold, palladium, and platinum using lignophenol derivative. Miner Eng 22(13):1173-1178

Ramesh A, Hasegawa H, Sugimoto W, Maki T, Ueda K (2008) Adsorption of gold(III), platinum(IV) and palladium(II) onto glycine modified crosslinked chitosan resin. Bioresour Technol 99(9):3801-3809

Ren P, Yue SL, Zhang ZL et al (2007) Study on the extraction of tannin from pomegranate rind. Food Ind Technol 28(1):149-150

Xiong Y, Adhikari CR, Kawakita H, Ohto K, Inoue K, Harada H (2009) Selective recovery of precious metals by persimmon waste chemically modified with dimethylamine. Bioresour Technol 100(18):4083-4089 